\title{
The Relative Strength of Preferences for Association with Coethnics: Malay-Malaysians and Chinese-Malaysians
}

\author{
Mansor Mohd Noor and Nor Idayu Mahat
}

\begin{abstract}
This paper studies the strength of preferences of two major ethnics in Malaysia, Malay-Malaysians and Chinese-Malaysians. Also, the study observes changes of association between these ethnics over period of times. The study utilized a survey research design which had been collected since year 1990 to year 2013. The survey was designed to measure the ethnic preferences over individual self-interest of material kind, social status and personal obligation. The empirical results indicate some inequalities on ethnic preferences between the Malay-Malaysians and the Chinese-Malaysians in early 1990s, but both ethnics illustrate similar preferences in 2000s. The computed social alignment score demonstrates the tolerance of both ethnics on material and personal obligation, but the ethnic choice is much preferred than the social status. In relative, individual self-interests are much developed among the Malay-Malaysians compared to the Chinese-Malaysians.
\end{abstract}

Index Terms-Diversity, ethnicity, social alignment, social index.

\section{INTRODUCTION}

Reference [1] identified four paradigms formed in Malaysia, a multicultural country with more than 80 ethnics, which include ethnicity, class, culture and identity. These paradigms are believed established by the colonials that divided the ethnics based on segment of economies during the colonial era. Diversities in each paradigm have led Malaysia been described as a minefield of cultural sensitivities [2], hence may influence the development of economy, selection of employees [3], working values [4] and much more. However, [1] believes that the four paradigms are temporary as the demographics of Malaysia may change influenced by the economic development, migration of people, political growths as well as demographic changes in the region.

Vision 2020, launched in 1991, identifies nine challenges faced by Malaysia in the excursion to achieve a self-sufficient industrialized nation by the year 2020. One of which, the most important one is establishing a united Malaysian nation towards the ultimate objective [5]. Later in 2010, the 1Malaysia concept was introduced to emphasize the importance of national unity regardless of race, background or religious belief [6]. Under this concept,

Manuscript received March 6, 2015; revised August 20, 2015.

Mansor Mohd Noor is with the Institute of Ethnic Studies, Universiti Kebangsaan Malaysia, 43600 Bangi, Selangor, Malaysia (e-mail: mnmansor@ukm.edu.my).

Nor Idayu Mahat is with the School of Quantitative Sciences, Universiti Utara Malaysia, 06010 UUM Sintok, Kedah, Malaysia (e-mail: noridayu@uum.edu.my). several values inculcate among Malaysians including culture of excellence, perseverance, humility, acceptance, loyalty, meritocracy, education and integrity. As the unity has become a concern, therefore social alignment in the society needs to be well managed where evidence from social alignment may reflect the tolerance among ethnics.

Lately, the issues of ethnic relations often be highlighted by media especially blogs. It cannot be denied that sometimes, the ethnic issues and sensitivities are used as election materials campaign. Is it true that after half century Malaysia be independence, the social relations between ethnics still shallow?

This paper reports the findings on research that was conducted based on series of surveys on two major ethnics in Malaysia namely Malay-Malaysians and Chinese-Malaysians. Historically, the Malay-Malaysian is the indigenous race in Peninsular Malaysia while the Chinese-Malaysian is believed had been migrated from some parts of China due to economy opportunities during the colonial era. The discussion focuses on the social alignment between these two ethnics in period of times.

Section II of this paper overviews past studies related to ethnic studies and social alignment, Section III elaborates the details of the investigation for measuring the alignment of the ethnics, Section IV demonstrates the results and the final section summarises the discussion.

\section{Social Alignment AmONG ETHNics}

Development of ethnic studies adopts the concept of ethnicity as a limit, which lead to studies on ethnic identity [7], [8]. Then, the ideas of conceptual ethnicity framework have been used as a foundation by [9] and [10] to learn about religious conflict in India. He discovered that a group of Hindus and Muslims in the cities that managed to build cross-institutional religious relations are able to avoid clashes in the communities. Later, [11] quoted that if security dialogue can bring in ethnic and religious groups to discuss among themselves, then the clashes groups can definitely be managed.

In Malaysia, understanding of human society from the dimension of language, culture, religion, family and region is practiced. It is believed that human behavior is largely influenced by the culture of life compared to genetic influence [12], [13]. Earlier studies agree that social interest especially material creates collaborative network among ethnic groups [14]-[16]. Ethnicity, language, culture and religion are shaping the identity of individual, but social differences play as important roles in increasingly shaping society in Malaysia. Thus, it opens the practice of multiple 
social identities in the society.

In social study, when one acts, he will close other choices and build a relationship with other individuals thus develop social ties among them. Such social ties can be stronger than the primary ties, e.g. ties due to family relationship. It means cross-ethnic social ties may develop social relationship across groups. Therefore, it is important a continuous study on ethnic relations to be done so that shortcomings in society can be identified and control measures can be implemented to secure prosperity.

\section{Methodology}

\section{A. Data}

This study used secondary data based on series of survey collected from researches conducted from 1990 to 2013 and presented by [17]. The original surveys included other ethnics in Malaysia, such as Indians, Kadazan, Bidayuh and Siamese, with diversity backgrounds, for example housing scheme residences, industrial workforces, university students and communities in the country. However, this study focuses to compare the preferences of Malay-Malaysians and Chinese-Malaysians in attempt to measure social alignment between these two major ethnics. The rest parts in this paper will use "Malay" for Malay-Malaysians and "Chinese" for Chinese-Malaysians.

The secondary data sets consist of the same number of variables for measuring ethnic preferences and individual self-interest, but the sizes of sample vary from year to year where the samples are in range of 300 to 6,000 respondents.

\section{B. Instruments and Variables for Measuring Social Alignment}

Reference [17] used a questionnaire that was designed to analyze the influence of ethnic versus universal norms in an individual. Each item in the questionnaire assesses to which dimension relatively more influence upon individual's choice. Ethnic dimension is represented by a given name of ethnic and universal norms are represented by three; personal interests towards (i) material kind, (ii) social status and (iii) personal obligation on social demands.

The questionnaire contains structured questions which written in a form of scenario or conflict, rather than a direct form such as "do you possess strong ethnic identity?" or "do you mind to rent a house to a Chinese man?". For each conflict, one is required to choose an option which best represent his choice. If one chooses to act on ethnic choices, it shows he is bold with ethnic boundaries in attempt to secure his advantage. However, if he opts to material universal norms, social status and personal obligation, it means that individual choice has been given as a priority. Such technique of social cohesion examines how an individual makes a choice of action in life by choosing one action relative when compared with others.

As for this paper, all responses from respondents were converted into percentage of choices on individual selfinterests (material kind, social status and personal obligation) and ethnic preference. Then, these percentages are used to measure the social alignment, in other words, the association between the Malay and Chinese.

\section{Computation of the Social Alignment}

Common presentations based on figures or simple statistics measures (e.g. average and standard deviation) are easy, but those methods could not present the association between the ethnics. Therefore, this study uses a comparison strategy so that the tolerance between the investigated ethnics can be easily dictated.

Ethnic preference over social preference (individual self-interest) between Malay and Chinese was computed using Social-Ethnic Alignment Index (SEA index). First, a social alignment score (SA score) was computed on each ethnic by dividing the percentage of responses between the ethnic preference over the social interest. The score takes values from $0 \%$ to $100 \%$, which give a signal whether the investigated ethnics are being bounded to ethnic boundary or the social interest.

For example, if the SA score for Malay on material kind is less than $45 \%$, it indicates that the Malay communities are positioning the importance to secure their material kind rather than the ethnic choice. However, if the score is greater than $55 \%$, it shows that Malays are considering the ethnic value as much important in their decision making. Meanwhile, the score between $45 \%$ and $55 \%$ are termed as a moderate social alignment.

Next, the computed SA scores were used to calculate the association (Social Index) between the Malay and the Chinese. The index is merely the odds ratio of the SA score between the Malay and the Chinese. The index functions to guide researchers on the direction of the preference of the ethnics. Details on the interpretations of the index are summarized in Table I.

TABLE I: THE INTERPRETATION OF THE SOCIAL INDEX

\begin{tabular}{|c|c|}
\hline Social Index & Interpretation \\
\hline More than 1 & $\begin{array}{l}\text { The social preferences are more likely to occur in } \\
\text { Malay. }\end{array}$ \\
\hline 1 & $\begin{array}{l}\text { The social preferences are equally likely to occur } \\
\text { in both ethnics. }\end{array}$ \\
\hline 0 to 1 & $\begin{array}{l}\text { The social preferences are less likely to occur in } \\
\text { Malay (but more likely to occur in Chinese). }\end{array}$ \\
\hline-1 to 0 & $\begin{array}{l}\text { The ethnic preferences are less likely to occur in } \\
\text { Malay (but more likely to occur in Chinese). }\end{array}$ \\
\hline-1 & $\begin{array}{l}\text { The ethnic preferences are equally likely to occur } \\
\text { in both ethnics }\end{array}$ \\
\hline Less than -1 & $\begin{array}{l}\text { The ethnic preferences are most likely to occur in } \\
\text { Malay. }\end{array}$ \\
\hline
\end{tabular}

\section{RESUlts}

\section{A. Patterns of Ethnic Preference among Malay and Chinese}

Table II shows the percentage difference between the three social interests (i.e. material kind, social status and personal obligation) of both ethnics. Large value of difference indicates that one of the ethnic give higher importance toward ethnic preference than the social interest. It means, the ethnicity group boundary presents in the community. Whilst, low value of difference shows that both ethnics have similar preferences, either towards ethnic choice or social interest. Also, the table lists years of available data used in 
this paper. Due to some constraints, some years are unavailable to be included in this study, but the changes of ties between the ethnics still can be detected.

In general, Table II shows some gaps of preferences between the two ethnics. The gaps are big in the early years of 1990s which can be seen in columns of material kind and social status Table II. Such scenario shows that there was ethnicity preference occurred in one of the investigated ethnic when dealing with making a choice which related to material kind and social status. However, the size of gaps is smaller as the year increases which portray that the two ethnics are aligning themselves to similar preferences.

Among the three social interest, both ethnics show similar preference when the choice deals with personal obligation. This indicates that both ethnics will opt to perform similar actions when they are facing conflicts that involve individual commitments. In average, the largest inequality between the ethnics is recorded by social status. It reflects that one make a choice by considering ethnic type, perhaps due to influence of others. For example, a Malay man could choose to attend a ceremony of his Malay's friend compared to his Chinese's friend. In such a decision, his consideration is influenced by the fact he wants to be at an event that fit to his religious belief and suitable with his practices. Starting somewhere in year 2000, the inequalities on social status are getting smaller influenced by new polarization of people. Malays and Chinese stay together either at the rural and urban areas, eliminate the deviation of ethnicity settlement which earlier practiced by the colonials.

TABLE II: THE DIFFERENCES OF ETHNICITY STRENGTH BETWEEN MALAY AND CHINESE

\begin{tabular}{llll}
\hline \hline \multirow{2}{*}{ Year } & \multicolumn{3}{l}{ Ethnicity strength over social interest (percent) } \\
\cline { 2 - 4 } & Material kind & Social status & Personal obligation \\
\hline \hline 1990 & 15.33 & 28.25 & 9.50 \\
1992 & 9.33 & 11.75 & 5.67 \\
1993 & 9.42 & 4.50 & 4.83 \\
1995 & 11.67 & 8.50 & 7.67 \\
1996 & 8.33 & 13.25 & 5.50 \\
1998 & 4.83 & 7.25 & 3.17 \\
1999 & 4.83 & 7.50 & 3.67 \\
2000 & 7.67 & 7.25 & 7.00 \\
1998 & 6.50 & 7.75 & 5.33 \\
1999 & 7.76 & 6.38 & 7.97 \\
2000 & 5.59 & 6.25 & 5.80 \\
2001 & 4.77 & 6.24 & 3.00 \\
2005 & 6.24 & 4.65 & 4.88 \\
2006 & 10.95 & 3.63 & 4.05 \\
2007 & 15.33 & 28.25 & 9.50 \\
2009 & 9.33 & 11.75 & 5.67 \\
2010 & 9.42 & 4.50 & 4.83 \\
2011 & 7.70 & 6.80 & 4.20 \\
2012 & 10.70 & 6.70 & 0.60 \\
2013 & 0.01 & 0.03 & 0.03 \\
\hline \hline
\end{tabular}

Although Table II highlights the present of ethnic preference in the community, actual behavior of the investigated ethnics is not well understood. Therefore, social alignment score (SA score) was computed to reveal the preferences direction of these ethnics.

Fig. 1 shows the patterns of preferences, i.e. ethnic versus material kind, for Malay and Chinese across years of study. Earlier, TABLE II indicated some gaps between the ethnics in early 1990s, later tie together around year 2000. In details, Fig. 1 shows that the social alignment for both ethnics located in "material kind boundary", which means that both ethnics are more concern to material kind than limited themselves to ethnic preferences.

Although the gaps exist, the ethnic preference is losing as one feels that securing physical needs in term of material kind, e.g. business partner, giving loan, retails activities etc., is much important than restricting oneself to akin ethnic.

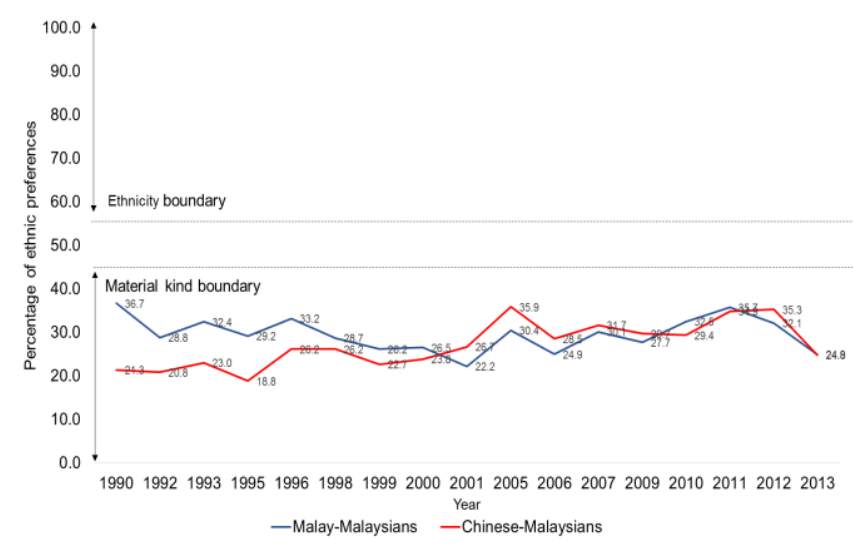

Fig. 1. Ethnics' alignment between ethnic preference and material kind.

However, ethnic preference comes important to Malay and Chinese when dealing with conflicts related to social status. Fig. 2 shows that Malays stick to greater ethnicity boundary in 1990 than the Chinese, but both ethnics gradually develop their ethnicity priority across years. This finding shows that both Malays and Chinese are facing some barriers to allow themselves to tolerate in conflicts that involve social status.

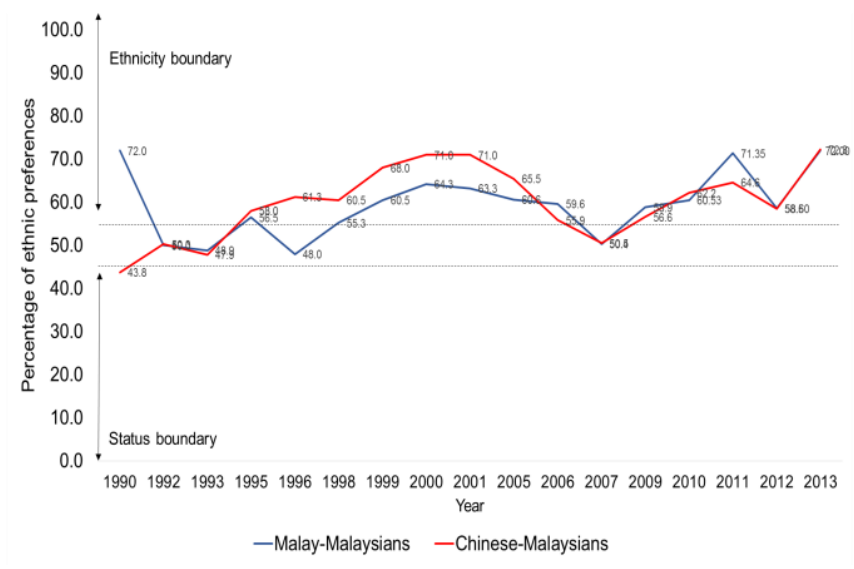

Fig. 2. Ethnics' alignment between ethnic preference and social status.

In contrary to Fig. 2, Fig. 3 reveals that ethnicity preference is unimportant to both ethnics when facing with conflicts related to personal obligation. In normal society where multi-ethnicities present, one usually does not restricting oneself to ethnic choice to decide, e.g. to whom to buy things, to pay condolence, to work in a team etc. Thus, in Malaysia, the Malays and the Chinese are having good relationship and toleration.

Comparison on Fig. 1 to Fig. 3 provides some important features about the behavior between Malay and Chinese. Careful view on each figure shows that Chinese community has lesser ethnicity belief compared to Malay community in early year of investigation. Then, the belief is gradually 
increases and getting close to the Malays. The largest fluctuation on the size of changes among the Chinese can be seen in Fig. 2. Meanwhile, the Malay communities do not many changes in term of percentage ethnic preferences, except the one depicted in Fig. 2.

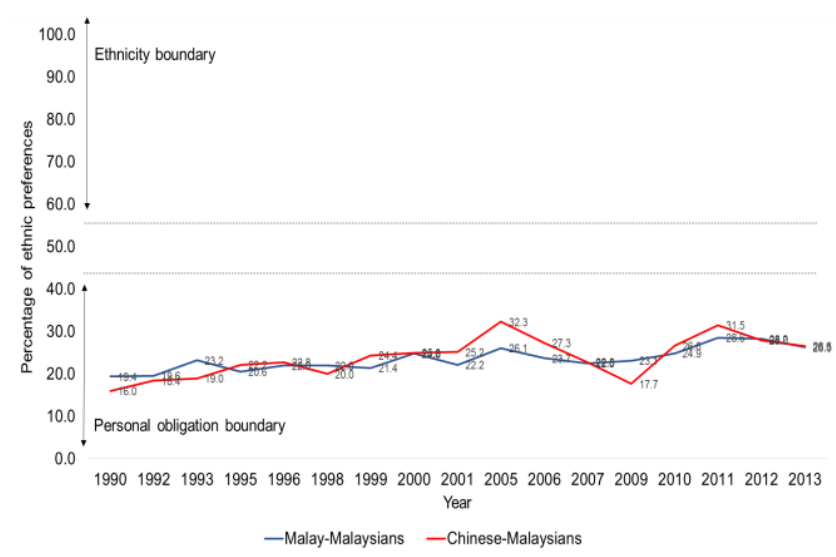

Fig. 3. Ethnics' alignment between ethnic preference and personal obligation.

\section{B. Strength of Social Alignment between Malay and Chinese}

Next investigation measures the relative association between Malay and Chinese. Fig. 4 displays the association score between the two ethnics and shows the dimension of alignment. Details interpretations of the boundaries are given in Table I.

Overall, association between the Malay and the Chinese are good as the ethnic boundaries thinned, and both ethnics are found to build ties and social relations. The association appears to be based on social interest rather than ethnic as the social index for material kind and personal obligation are always residing in social preference boundaries. However, ethnic choice is discovered, especially among the Chinese, when dealing with social status.

In term of material kind and personal obligation, the Malay show much higher preference towards these social ties with the Chinese. Such toleration influence social relations between the two ethnics, as the Chinese do not put great ethnic preference in these interests. With the establishment of cross ties and social groups, social cohesion is built among the people of various ethnic groups and is different from the description of the relationship between the weak, strained and potential conflicts posed by certain groups.

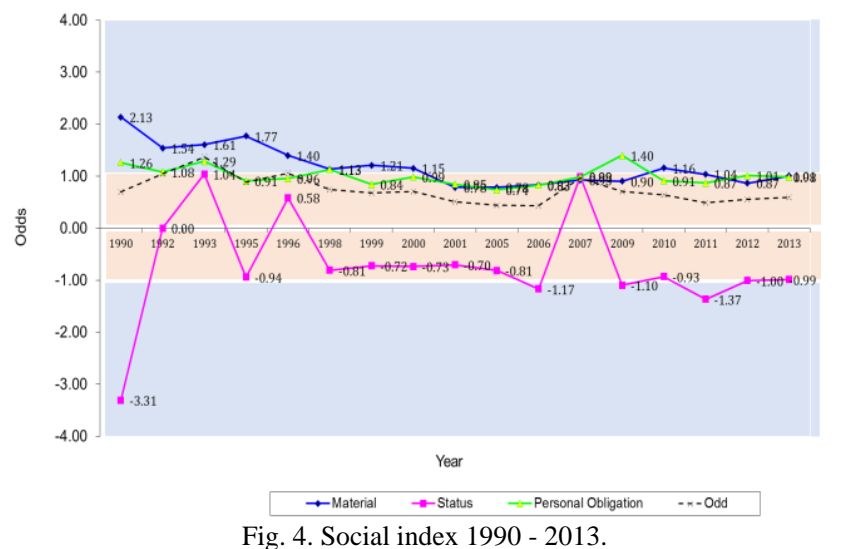

The ethnic preference presents greater in Chinese group when dealing with social status in most years of study. However, the last two years of study show that Malays start to bound with ethnic preference in this type of social interest. This finding could be explained by the fact that, somehow, other factors may influence the ties between the ethnics when involve with social status such as religious belief.

\section{DISCUSSION AND CONCLUSION}

The evidence gather from the analyses in Section IV shows that the Malay and the Chinese in Malaysia establish good social ties. The patterns of social tie depicts that both ethnics show similar preferences in all social interest. In details, both ethnics prefer to give priority on material kind and personal obligation than to ethic choice. And, both ethnic opt to show ethnic preference than social status. Beside, a collective of social indexes for several years is useful to show the tolerance among the ethnics after the government has been putting so much effort in developing the nationhood through education, economics structure, health and much more. At least, some precautions can be considered if the patterns indicate greater movement towards extremist ethnic preference.

All findings show that the social reality of ethnic relations in Malaysia is better when compared to the negative perceptions that would be displayed by political, media and bloggers. However, the positive effects of educational progress, modernization and formation of class and middle-class culture among the people of various ethnic groups cannot be considered to be constant over time. As the country grows much faster with higher income per capita, the gap between rich and poor will grow regardless of ethnic backgrounds. The socio-economic losers among low income groups and social transformation of this country will become critical and anti-government, and if not managed properly the risk of their lives, can turn and lead to social tension prevailing ethnic and religious conflicts.

\section{REFERENCES}

[1] S. A. Baharudin, "Ethnicity, class, culture or identity? Comparing paradigms in Malaysian studies," Akademika, vol. 53, pp. 61-76, 1999.

[2] A. Abdullah and L. Lim, "Cultural dimensions of Anglos, Australians and Malaysians," Malaysian Management Review, vol. 36, no. 2, pp. 1-17, 2001.

[3] A. T. Manshor, M. Jusoh, and M. Simun, "Diversity factors and preferential treatments in selecting employees," Journal of Management Development, vol. 22, no. 7, pp. 643-656, 2003.

[4] R. Fontaine and S. Richardson, "Cultural values in Malaysia: Chinese, Malays and Indians compared," Cross Cultural Management: An International Journal, vol. 12, no. 4, pp. 63-77, 2005.

[5] Economic Planning Unit. (February 2013). Vision 2020, 1991-2020. [Online]. http://www.epu.gov.my/en/wawasan-2020-1991-2020.

[6] Klik. (March 2015). 1 Malaysia. [Online]. Available: http://www.pmr.penerangan.gov.my/index.php/1malaysia.html

[7] T. Y. Eriksen, Ethnicity and Nationalism, London: Pluto Press, 1993.

[8] S. A. Baharudin, "Anthropology, identity, and nation formation in Malaysia" in Asian Anthropologies: The Making of Anthropology in East and Southeast Asia, New York: Oxford Berghahn Books, 2004, pp. 286-306.

[9] A. Varshney, "Ethnic conflict and civil society: India and beyond," World Politics, vol. 53, no. 3, pp. 262-298, 2001.

[10] A. Varshney, Ethnic Conflict and Civic Life: Hindus and Muslims in India, New Haven: Yale University Press, 2002. 
[11] I. Svensson, The Nagorno Karabakh Conflict: Lessons from the Mediation Efforts, Initiative for Peace building, Brussels: The Crisis Management Initiative (CMI), 2009.

[12] R. Herrenstein and C. Murray, The Bell Curve: Intelligence and Class Structure in American Life, New York: Free Press, 1994.

[13] D. D'Souza, The End of Racism: Principles for a Multiracial Society, New York: Free Press, 1993.

[14] S. A. Baharudin, From British to Bumiputera Rule, Singapore: Institute of Southeast Studies, 1986

[15] J. Jesudason, Ethnicity and the Economy: The State, Chinese Business, and Multinationals in Malaysia, Singapore: Oxford University Press, 1989.

[16] F. L. K. Wah and J. Saravanamuttu, New Politics in Malaysia, Singapore: Institute of Southeast Asian Studies, 2003.

[17] M. M. Noor, Kerencaman Sosoal dan Penipisan Batas Etnik: Kepelbagaian Etnik dan Perkongsian Hidup Bersama di Malaysia, Bangi: Universiti Kebangsaan Malaysia, 2012.

Mansor Mohd Noor is a professor in the sociology of ethnic relations. At present he is attached as a principal research fellow and the head of the Cluster of Ethnicity and the Workplace at the Institute of Ethnic Studies (KITA), Universiti Kebangsaan Malaysia. He obtained his bachelor degree from USM, master degree from University of Canterbury, Christchurch, New Zealand and Ph.D. from University of Bristol, United Kingdom. Among his publications are "The study of ethnic alignment: A new technique and an application in Malaysia," Ethnic and Racial Studies, Banton and Mansor, vol. 15, no. 4, pp. 1992:599-613, "Crossing ethnic Borders in Malaysia: Measuring the fluidity of ethnic identity and group formation" Akademika, vol. 55, 2000, pp. 61-82. (Journal of anthropology and Sociology Universiti Kebangsaan Malaysia), " and "Multiculturalism or indigenous canopy? Making sense of the different trajectories of pluralism in southeast Asia," TINGKAP Jurnal Ilmiah Ilmu-ilmu Sosio Budaya dan Ekonomi, vol. 6, no. 2, 2011, pp. 53-66.

Nor Idayu Mahat is a senior lecturer in the School of Quantitative Sciences with major interests in multivariate analysis, statistical modelling and pattern recognition. At present, she is attached as a deputy director at Centre of Testing, Measurements and Appraisal (CeTMA), Universiti Utara Malaysia. She obtained her bachelor degree and master degree from Universiti Kebangsaan Malaysia, Malaysia, in statistics. Later, She completed her PhD from University of Exeter, United Kingdom. She practices her quantitative discipline in various areas including engineering, medicine, business and management, and currently she is cooperated with Institute of Ethnic Studies (KITA), Universiti Kebangsaan Malaysia, in investigating ethnics relations. 